UNIVERSITY OF FLORIDA

Cooperative Extension Service Institute of Food and Agricultural Sciences

Nombre

Teléfono

Dirección

Ciudad

Fecha

E-mail

Laboratorio de Extensión de Análisis de Suelos

PO Box 110740 / Wallace Building 631, UF / Gainesville, FL 32611-0740

SOILSLAB@MANOX

http:/soilslabifas ufledu/

\title{
Hoja de Información de Análisis de Aguas
}

Nota: Este Laboratorio solo analiza muestras del Estado de la Florida.

Dirija cualquier pregunta sobre esta prueba o sobre la interpretación de los resultados a su Agente de Extensión de su condado
NOTA: Estos análisis no determinan si el agua es para consumo humano. Pruebas bacteriológicas podrían estar disponibles en el Departamento de Salud del Condado

o en selectos laboratorios comerciales

\begin{tabular}{|c|c|c|c|c|c|c|c|c|c|c|c|c|c|}
\hline \multicolumn{14}{|c|}{ Llene toda la información solicitada, usando una línea por muestra y hojas adicionales por mas de 5 muestras. } \\
\hline \multirow{3}{*}{ 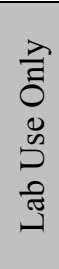 } & \multirow{3}{*}{ 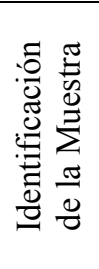 } & \multirow{3}{*}{$\begin{array}{l}\frac{8}{0} \\
\frac{\pi}{0} \\
0 \\
0\end{array}$} & \multirow{3}{*}{$\stackrel{n}{\stackrel{n}{\Xi}}$} & \multicolumn{5}{|c|}{ Fuente de la Información del Agua } & \multicolumn{3}{|c|}{ Información sobre uso del agua } & \multicolumn{2}{|c|}{ Costo } \\
\hline & & & & \multirow{2}{*}{$\begin{array}{c}\text { Pozo } \\
\text { Chequeo }\end{array}$} & \multicolumn{3}{|c|}{$\begin{array}{l}\text { Si es pozo, especificar } \\
\text { localización y profundidad }\end{array}$} & \multirow{2}{*}{$\begin{array}{c}\text { Superficie } \\
\text { Chequeo }\end{array}$} & \multirow{2}{*}{ 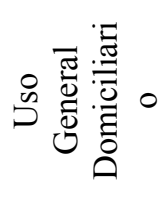 } & \multicolumn{2}{|c|}{ Riego } & & \\
\hline & & & & & Rango & Localidad & Sección & & & $\begin{array}{l}\text { Domicil } \\
\text { io }\end{array}$ & $\begin{array}{l}\text { Micro- } \\
\text { irrigación }\end{array}$ & & \\
\hline & & & & & & & & & & & & $\$ 10.00$ & $\$ 9.00$ \\
\hline & & & & & & & & & & & & $\$ 10.00$ & $\$ 9.00$ \\
\hline & & & & & & & & & & & & $\$ 10.00$ & $\$ 9.00$ \\
\hline & & & & & & & & & & & & $\$ 10.00$ & $\$ 9.00$ \\
\hline & & & & & & & & & & & & $\$ 10.00$ & $\$ 9.00$ \\
\hline
\end{tabular}

PROBLEMAS ESPECIALES OBSERVADOS:

Cheque

Money Order

Efectivo

Total

LAS MUESTRAS NO SERAN PROCESADAS SIN PAGO.

Por favor incluya el pago y esta hoja en el mimo paquete con la(s) muestra(s)

No envíe efectivo por el correo!evisado Agosto 2002 


\section{Instructions and Information for the Water Test Information Sheet}

\section{Como tomar una muestra representativa de agua}

Herramientas

1. Una botella plástica de 1 pinta para colectar la muestra. No use botellas de shampoo o de jabón ya que es difícil remover todos los residuos. Botellas de vidrio no son recomendables.

2. Una caja de cartón corrugado. Estas cajas (también usadas para enviar muestras de suelo) están disponibles sin cargo alguno en su oficina local del condado del Servicio Cooperativo de Extensión.

3. Algún material de empaque para empacar la muestra de tal manera que la muestra no se dañe o se pierda por fuga durante el envío al Laboratorio de Extensión de Análisis de Suelos.

4. Este formato. Use copias adicionales si usted planea enviar mas de 5 muestras de agua.

\section{Muestreo}

1. Permita que el agua corra por unos minutos en el punto de colección antes de tomar la muestra

Para muestras domiciliarias, permita el flujo de agua por varios minutos para asegurar que la muestra proviene directamente del pozo. El agua que se ha estancado en el conducto de la bomba por algún tiempo no es una muestra representativa.

Para muestras de irrigación y micro-irrigación, muestree tan cerca de la fuente como sea posible para asegurar que la muestra representa la fuente de agua.
2. Enjuague el recipiente de la muestra y su tapa varias veces en el agua corriente. No use jabón o detergente durante este paso de enjuagado.

3. Llene completamente el recipiente con el agua que está saliendo de la fuente. Deje en el recipiente tan poco aire como sea posible. Cierre con la tapa inmediatamente después de llenar el recipiente para evitar cualquier fuga.

4. Rotule el recipiente y empáquelo cuidadosamente en la caja de envío previamente rotulada.

5. Incluya en la caja de envío:

- Su muestra(s) de agua rotulada(s)

- Esta Hoja de Información de Análisis de Aguas con toda la información solicitada en la página

- Un cheque o money order a la orden de a: IFAS Extension Soil Testing Laboratory

Envie su muestra por correo a:

UF/IFAS ESTL

PO Box 110740

Wallace Bldg. 631

Gainesville, FL 32611-0740

\section{Análisis de Aguas - Ayuda para el diagnóstico de problemas}

Las detrminaciones químicas y físicas realizadas en el Laboratorio de Extensión de Suelos puede ser usado efectivamente en el diagnóstico de problemas potenciales en el agua. Sin embargo, el laboratorio no analiza la suitabilidad del agua para consumo humano. Análisis bacteriológicos pueden estar disponibles en el Departamento de Saludos del Condado o en laboratorios comerciales selectos.

\section{Resultados del Análisis}

Este reporte del análisis, será enviado a usted entre 5 a 10 días después de que la muestra haya arribado al Laboratorio de Extensión de Suelos. Contacte a su oficina de Extensión del condado si usted tiene preguntas relacionadas con los resultados.

\begin{tabular}{|l|l|l|}
\hline \multicolumn{2}{|c|}{ Potential Water Quality Problems } \\
\hline Tests & Irrigation (including microirrigation) & Household \\
\hline $\mathrm{Ca}, \mathrm{Mg}, \mathrm{y}$ carbonatos totales & Encalado potencial / problemas de obstrucción & Agua dura \\
\hline $\mathrm{Fe} \mathrm{y} \mathrm{Mn}$ & Follaje sucio / problemas de obstrucción & staining, taste \\
\hline $\mathrm{Na} \mathrm{y} \mathrm{Cl}$ & Intrusion de agua salada, daño a las plantas & salt water intrusion \& landscape plant damage \\
\hline $\mathrm{Conductividad} \mathrm{Electrica}$ & Daño de plantas derivado del alto contenido de sales & plant damage from high salt content \\
\hline $\mathrm{pH}$ & corrosión potencial / obstrucción & corrosion \\
\hline Solidos Suspendidos & Problemas de obstrucción & - \\
\hline
\end{tabular}

